\title{
Supratherapeutic Doses of Angiotensin Receptor Blockers to Decrease Proteinuria in Patients with Chronic Kidney Disease
}

\author{
Biff F. Palmer \\ Internal Medicine, Division of Nephrology, University of Texas Southwestern Medical Center, Dallas, Tex., USA
}

\section{Key Words}

Chronic kidney disease $\cdot$ Proteinuria $\cdot$ Supratherapeutic

doses $\cdot$ Angiotensin receptor blockers •

Renin-angiotensin-aldosterone system

\section{Abstract}

An important endpoint in treating chronic kidney disease, a prevalent disease that can lead to kidney failure and cardiovascular disease, is reducing proteinuria. Proteinuria is an independent risk factor for disease progression and the development of cardiovascular disease and is a key factor that can be used to guide therapy designed to maximize kidney protection. Proteinuria is targeted by using pharmacologic agents that suppress the renin-angiotensin-aldosterone system (RAAS), a regulator of intravascular volume and blood pressure; this has been shown to decrease proteinuria, slow disease progression, and improve coronary disease outcome, independent of effects on blood pressure. The efficacy of RAAS blockers, including angiotensin receptor blockers and angiotensin-converting enzyme inhibitors, may be limited by currently recommended doses, which are based on treatment of hypertension. Data are now emerging from clinical trials demonstrating that use of 'supratherapeutic doses' (doses greater than those approved for lowering blood pressure), compared with standard doses, has favorable safety, tolerability, and efficacy in reducing proteinuria in both diabetic and nondiabetic patients with chronic kid-

\section{KARGER}

Fax +41613061234

E-Mail karger@karger.ch

www.karger.com (c) 2007 S. Karger AG, Basel

0250-8095/08/0283-0381\$24.50/0

Accessible online at:

www.karger.com/ajn ney disease. Supratherapeutic dosing may be a valuable approach for optimizing RAAS blockade and providing renoprotection.

Copyright $\odot 2007$ S. Karger AG, Basel

\section{Introduction}

Chronic kidney disease (CKD) is a common progressive disease that can lead to kidney failure and development of cardiovascular disease [1]. It is estimated that $16.8 \%$ of adults in the United States have CKD: $11.1 \%$ have stage 1 or $2,5.4 \%$ have stage 3 , and $0.4 \%$ have stage 4 or stage 5 disease according to the Third National Health and Nutrition Examination Survey (NHANES III) (19992004) [2]. According to the US Renal Data System (USRDS) survey of 230,000 patients with CKD (1998), $0.2 \%$ of US adults have stage 5 disease (kidney failure) [3]. The prevalence of CKD is rising, particularly among the elderly; according to a study of general Medicare patients, among those patients aged 75 years and older the rate of CKD more than doubled between 1997-1998 and 20032004 [3]. The risk of progression to end-stage kidney disease is also increasing, beyond the rate of increase in the prevalence of CKD. Based on data from NHANES II and NHANES III, from 1978 to 1991, the incidence of stages 3 and 4 CKD increased by $25 \%$, whereas the risk of progression to end-stage kidney disease increased by $70 \%$ [4]. 
The most common cause of end-stage kidney disease is diabetes mellitus, which accounts for $45 \%$ of new cases [3] and is itself a growing epidemic; the projected prevalence of diabetes is $11.5 \%$ in 2011 and $14.5 \%$ in 2031 [5].

The magnitude of proteinuria has emerged as a useful marker to gauge the risk of progressive kidney disease in both diabetic and nondiabetic CKD. Reducing urinary protein excretion is associated with a decrease in the rate of subsequent loss of kidney function, suggesting that maximal reduction in urinary protein excretion should be a therapeutic goal in the overall strategy to preserve kidney function in patients with proteinuric CKD. One of the most effective strategies to reduce proteinuria is stringent blood pressure control centered around the use of a renin-angiotensin-aldosterone system (RAAS) blocker. RAAS blockade has been shown to decrease proteinuria, slow the progression of CKD, and improve coronary disease outcome, independent of effects on blood pressure [6]. The efficacy of RAAS blockers in preserving kidney function may be limited by the use of currently recommended doses, which are based on blood pressurelowering effects for treating hypertension. Data are now emerging from clinical trials of the safety and efficacy of 'supratherapeutic' doses (doses greater than those approved for the lowering of blood pressure) of RAAS blockade in treating CKD. This article will review the rationale and available clinical trial data supporting the use of supratherapeutic dosing of angiotensin receptor blockers (ARBs) as a strategy to maximize the reduction in urinary protein excretion.

\section{Evidence Supporting Proteinuria as a Target for Therapy}

Proteinuria is an independent predictor of kidney disease progression. Baseline level of protein, magnitude of decrease in protein level, and residual protein after a period of treatment are all related to progression of kidney disease in patients with or without diabetes. In addition, proteinuria reduction was found to impact all major domains of the health-related quality of life (HRQOL) in a lagged and profound manner [7]. In patients enrolled in the Irbesartan Diabetic Nephropathy Trial (IDNT) with overt diabetic nephropathy and type 2 diabetes mellitus, doubling of baseline proteinuria level resulted in doubling of the risk for kidney failure (hazard ratio (HR) 2.04; 95\% confidence interval (CI) 1.87-2.22; p < 0.001); with 12 months of treatment with irbesartan, proteinuria levels were cut in half and the risk of kidney failure by more than 50\% (HR 0.44, 95\% CI 0.40-0.49; p < 0.001) [8]. Similar results were reported in patients enrolled in the Reduction in Endpoints in Noninsulin-Dependent Diabetes Mellitus with the Angiotensin II Antagonist Losartan (RENAAL) study. After adjusting for other risk factors, patients with high baseline albuminuria $(\geq 3.0$ $\mathrm{g} / \mathrm{g}$ creatinine) had a 5.2-fold increased risk of reaching a kidney endpoint and an 8.1-fold increased risk of progressing to end-stage kidney disease compared with patients with low levels of albuminuria $(<1.5 \mathrm{~g} / \mathrm{g})$. With 6 months of treatment with losartan, every halving of albuminuria levels in these patients was associated with a $36 \%$ reduction in the risk of a kidney endpoint and a $45 \%$ reduction in the risk of end-stage kidney disease [9].

There is a larger body of evidence that demonstrates a correlation between proteinuria and kidney endpoints in patients with nondiabetic nephropathy. The Modification of Diet in Renal Disease Study (MDRDS) was a twopart study of patients with CKD of different causes (insulin-dependent diabetic patients were excluded) treated by dietary protein restriction [18]. Study A included 585 patients with a glomerular filtration rate (GFR) of 25-55 $\mathrm{ml} / \mathrm{min} / 1.73 \mathrm{~m}^{2}$, and study B included 255 patients with a GFR of $13-24 \mathrm{ml} / \mathrm{min} / 1.73 \mathrm{~m}^{2}$. In both groups, at a mean of 2.2 years of follow-up, decline in GFR was faster in patients with higher achieved blood pressure during follow-up; this correlation was significantly stronger in patients with higher baseline proteinuria $(\mathrm{p}<0.001$ and $\mathrm{p}<0.01$, respectively). An initial decrease in proteinuria during the first 4 months was significantly associated with a slower subsequent decline in GFR in both study A and study B. In a meta-analysis of 11 randomized controlled trials that included 1,860 patients with nondiabetic kidney disease in which patients were treated with an angiotensin-converting enzyme inhibitor (ACE-I), higher levels of proteinuria during follow-up were associated with greater risk of kidney disease progression (combined endpoint of doubling of baseline serum creatinine level or onset of end-stage kidney disease, defined as the onset of chronic dialysis therapy). It was found that there was a 5.56-fold greater risk of kidney disease progression (3.87-7.98) for each 1.0 -g/day elevation of protein excretion [10].

Proteinuria is also a risk factor for cardiovascular disease. In a large cohort study of the general population ( $n=40,548)$, higher urinary albumin concentration increased cardiovascular mortality and noncardiovascular mortality, even after adjusting for risk factors, including sex, age, diabetes mellitus, antihypertensive drugs, lipidlowering drugs, smoking, family history of cardiovascular disease, previous myocardial infarction, and previous stroke [19]. A 2-fold increase in urinary albumin concen- 
tration was associated with a significantly higher adjusted relative risk of cardiovascular mortality $(1.29 ; 95 \% \mathrm{CI}$ $1.18-1.40)$ versus noncardiovascular mortality $(1.12 ; 95 \%$ CI 1.04-1.12; $\mathrm{p}=0.014)$ [19].

\section{Monitoring Urinary Protein Excretion}

The National Kidney Foundation recommends monitoring proteinuria during the course of $\mathrm{CKD}$, and modifying the treatment regimen if high levels of proteinuria are found [1]. The upper limit of normal for total urinary protein excretion is $150 \mathrm{mg} / 24 \mathrm{~h}$. The majority of this protein consists of systemically derived small-molecularweight proteins filtered by the glomerulus and proteins derived from the kidney tubules and lower urinary tract. Present guidelines suggest that the normal excretion of albumin is $30 \mathrm{mg} /$ day, although emerging data suggest cardiovascular risk starts increasing at a much lower level of albuminuria. Some experts believe that the threshold of albuminuria is $10 \mathrm{mg} / \mathrm{g}$ of creatinine. Persistent albumin excretion between 30 and $300 \mathrm{mg} /$ day is considered microalbuminuria. Values $>300 \mathrm{mg} /$ day are considered overt proteinuria or macroalbuminuria. At this level of excretion, the standard urinary dipstick is positive and the bulk of urinary protein excretion is composed of albumin. Renoprotective effects can often be more easily detected in studies measuring reduction in proteinuria compared with reduction of microalbuminuria.

A variety of collection methods have been utilized for the measurement of urinary albumin excretion (UAE). Timed collections, either overnight $(8-12 \mathrm{~h})$ or for $24 \mathrm{~h}$, are common assays. However, since precisely timed urine collections are often impractical and inconvenient for many patients, the preferred method of measurement is to obtain a spot urine albumin-creatinine ratio. According to the National Kidney Foundation, a urine albumincreatinine ratio $<30 \mathrm{mg} / \mathrm{g}$ is normal, $30-300 \mathrm{mg} / \mathrm{g}$ is defined as microalbuminuria, and $>300 \mathrm{mg} / \mathrm{g}$ is defined as clinical nephropathy or macroalbuminuria [1]. Preferably, this ratio should be measured from values obtained from a first morning urine sample; otherwise, a random sample may be used. Semiquantitative dipsticks specific for albumin are available; however, they are subject to error as a result of variations in urine concentration caused by hydration status. The relatively constant excretion of creatinine throughout the day enables the albumin-creatinine ratio to overcome this limitation. This ratio is more reproducible and shows less variability than measurements which do not use the albumin-creatinine ratio [11].

Supratherapeutic Doses of ARBs to

Decrease Proteinuria in CKD
The total protein-creatinine ratio will give similar results and can be substituted for the albumin-creatinine ratio in patients with an albumin-creatinine ratio of $>500$ to $1,000 \mathrm{mg} / \mathrm{g}$, which corresponds to urinary protein excretion $>500$ to $1,000 \mathrm{mg} /$ day. However, the albumin-creatinine ratio should be used in the initial quantification of urinary protein excretion because albumin is a more sensitive marker than total protein in the early stages of CKD due to diabetes, hypertension, and glomerular diseases: the total protein-creatinine ratio may be within normal limits even though UAE has crossed into the microalbuminuric range.

\section{Strategies for Treating CKD Target the RAAS}

The RAAS plays a major role in the development of progressive CKD. The binding of angiotensin II to the AT1 receptor mediates the development of glomerular hypertension, resulting in hemodynamic changes associated with proteinuria, and glomerulosclerosis. Proteinuria may exacerbate kidney injury by causing kidney tubular cells to release proinflammatory cytokines that can lead to injury $[21,22]$. AT1 receptor activation by angiotensin II also stimulates production of cytokines and growth factors, such as transforming growth factor $\beta$, which promotes the development of glomerulosclerosis and tubulointerstitial fibrosis. Finally, AT1 receptor activation by angiotensin II also promotes the formation of free oxygen radicals, which accelerates the consumption of nitric oxide and can lead to endothelial dysfunction and hypertrophy of the kidney vasculature.

Monotherapy with ARBs or with ACE-Is has demonstrated antiproteinuric and renoprotective efficacy, largely independent of the blood pressure-lowering effect [6]. In an early study with captopril, an ACE-I, the immediate decrease in proteinuria did not coincide with a decrease in systemic blood pressure [12]. In the RENAAL study, nearly all of the renoprotective effect of losartan (an ARB) was explained by its antiproteinuric activity $(\sim 100 \%$ for the renal endpoint and 50\% for the ESRD endpoint) [9]. It is, however, important to note that the strength of the correlation between proteinuria and systolic blood pressure was found to be in the order of ambulatory blood pressure $>$ home blood pressure $>$ standardized clinic blood pressure, so that the relationship between proteinuria and blood pressure would be most apparent using measures of a mbulatory blood pressure [13]. To overcome potential limitations of treatment with either agent, one alternative approach to monotherapy is combination therapy with both ARBs and ACE-Is. ACE-Is may not completely block the generation of angiotensin II, due to 
the existence of alternative pathways of formation (e.g., via chymase and other serine proteases); with long-term use, there is evidence of a partial escape of ACE inhibition [6]. ARBs, on the other hand, selectively block the AT1 receptors, which in turn can cause overstimulation of AT2 receptors. Overstimulation of the AT2 receptors induces beneficial effects, such as an increase in vasodilation and a decrease in cellular proliferation. The binding affinity of ARBs for the AT1 receptor is generally high, and relative affinities are as follows: telmisartan $>$ olmesartan $>$ candesartan $>$ EXP3174 (active metabolite of losartan) $\geq$ valsartan $\geq$ losartan [14]. However, with long-term use of ARBs, there may be a compensatory increase in levels of angiotensin II, which may compete with and displace ARB from AT1 receptors [6]. ARBs also do not have some of the benefits of ACE-Is. ACE-Is increase plasma levels of bradykinin and other substances catabolized by ACE that have antifibrotic properties. Finally, the efficacy of both ACE-Is and ARBs may be limited by tissue penetration and pharmacokinetic profiles $[6,23]$. In one combination study, an ARB (losartan) was added to maximal, chronic ( $>3$ months) ACE-I therapy. Although this study showed a lack of effect with ARB added to high dose ACE-I, it was a short-term study performed in patients with substantially more severe kidney disease, worse hypertension and lower GFRs than seen in some previous studies. Larger trials with more long-term studies are required to address these results [15]. It is also possible that evidence of early kidney repair would be apparent if a more sensitive marker were used. Urinary markers of oxidative damage appear to respond to addon losartan therapy independently of a reduction in proteinuria or blood pressure, and these changes occur before measurable changes in plasma markers of oxidative stress [16].

A large randomized controlled study, the Ongoing Telmisartan Alone and in Combination with Ramipril Global Endpoint Trial (ONTARGET), is currently under way to assess long-term kidney outcomes of adding telmisartan $80 \mathrm{mg} /$ day to ramipril $10 \mathrm{mg} /$ day in high-risk patients or in those with controlled hypertension [24] Subjects include 25,620 patients with coronary, peripheral, or cerebrovascular disease or diabetes with end-organ damage. Results will be presented at the 2008 conference of the American College of Cardiology [25], and will help us to understand whether combination ACE-I/ARB or high-dose monotherapy is the more effective choice.

The antiproteinuric and renoprotective effects of RAAS blockade may be enhanced by dietary protein restriction, salt restriction and the use of diuretics. It has been shown that high dietary salt can block the effect of pharmacologic RAAS blockade [27]. Smoking is also a significant risk factor for proteinuria, as a $32 \%$ increased risk was observed in a large epidemiologic study of people with normal kidney function [28]. Statins and other lipidlowering drugs may reduce proteinuria and provide renoprotection [29]. Preliminary studies suggest targeting RAAS at other levels such as the inhibition of aldosterone or renin, which may also reduce proteinuria [30-32]. Readily available clinical strategies designed to lower urinary protein excretion have been the subject of a recent review [33].

\section{Safety of Supratherapeutic Dosing}

Another approach to maximize RAAS blockade is the use of supratherapeutic doses of ARBs. Doses of ACE-Is and ARBs have been optimized for reducing blood pressure, not reducing occurrence of kidney endpoints [34]. High doses of ACE-Is have been studied in clinical trials but have produced conflicting results as to whether doses that no longer affect blood pressure still exert additional antiproteinuric effects. There is virtually no data specifically examining effects on urinary protein excretion using doses above what is approved for the treatment of hypertension. In some cases, high doses of ACE-Is have been accompanied by a high frequency of adverse events, potentially limiting the use of these agents at supratherapeutic doses [35]. Also, high doses of captopril, when first introduced into clinical practice, were found to be occasionally accompanied by the development of membranous glomerulopathy [36-38].

Due to the fact that the adverse effect profile of ARBs is not dose-related, there has been a great deal of interest in exploring the use of supratherapeutic doses of ARBs as a way to maximize kidney protection. In an open-label trial in 12 patients with a history of diabetic or nondiabetic CKD, 8 weeks of treatment with candesartan titrated to a target of $160 \mathrm{mg} /$ day, which is 5 times the approved maximum dose, resulted in no serious drug-related adverse events and no significant change from baseline in serum creatinine level or plasma potassium levels [39]. In another study, 48 patients with reduced GFR (estimated GFR $53 \pm 23 \mathrm{ml} / \mathrm{min}$ ) treated with doses of ARBs 1.5-5 times the maximum approved doses were observed for 40 \pm 24 months (range 6-98 months) [40]. Patients in this study were administered candesartan cilexetil $(\mathrm{n}=34)$, valsartan $(n=6)$, losartan $(n=6)$, irbesartan $(n=3)$ and olmesartan $(n=2)$. There was a trend for increases in concentrations of serum potassium $(0.2 \pm 0.9 \mathrm{mmol} / \mathrm{l})$ and creatinine $(0.3 \pm 0.7 \mathrm{mg} / \mathrm{dl})$ at $3-4$ times the maxi- 
mum ARB doses, but only to levels 12 and 20\% higher than baseline values, respectively.

\section{Experimental Rationale of Supratherapeutic Dosing}

Clinical trials of supratherapeutic doses of ARBs were motivated by results of preclinical studies demonstrating cardioprotection and renoprotection with supratherapeutic doses. In a model of renovascular hypertension, treatment with high doses of an ARB or ACE-I inhibited activation of the RAAS and suppressed progression of various cardiac endpoints: systolic hypertension, cardiac hypertrophy and fibrosis, upregulation of cardiac collagen types I and III messenger RNA and atrial natriuretic peptide messenger RNA [41]. In a model of hypertension, high-dose treatment of an ARB or ACE-I normalized systolic hypertension, collagen content in the heart and kidney, and mesenteric small artery media-to-lumen ratio and reduced left ventricular weight-to-body weight ratio [42]. In a model of glomerulosclerosis (5/6 nephrectomy), treatment with a dose of an ARB several times higher than the dose currently used for blood pressure lowering dose-dependently arrested kidney inflammation and glomerular/interstitial injury and promoted regression of hypertension and albuminuria [43]. Renoprotection may be mediated by inhibition of extracellular matrix degradation. In one model, treatment with high doses of an ARB or ACE-I decreased progression of sclerosis in association with levels of plasminogen activator inhibitor1 , a proteinase inhibitor induced by angiotensin and activation of the AT1 receptor [44]. In a recent study using a model of kidney injury with hypertension, long-term treatment with high doses of an ARB dose-dependently increased angiotensin receptor blockade and decreased proteinuria, kidney inflammation, and macrophage infiltration. Treatment reduced blood pressure in a dosedependent fashion, and suppressed nuclear factor $\mathrm{\kappa B} \mathrm{ac-}$ tivation and chemokine expression [45].

\section{Clinical Data for Supratherapeutic Dosing}

A double-blind, randomized, crossover trial in $52 \mathrm{pa}-$ tients with hypertension, type 2 diabetes mellitus, and microalbuminuria, showed that supratherapeutic doses of irbesartan provide additional renoprotection and were well tolerated [46]. Patients received 2 months of treatment with irbesartan 300,600 , or $900 \mathrm{mg} /$ day. Irbesartan is indicated at $300 \mathrm{mg} /$ day for treating diabetic nephropathy in patients with elevated serum creatinine levels, and proteinuria ( $>300 \mathrm{mg} / \mathrm{day})$ in patients with type 2 diabetes mellitus and hypertension [47]. Treatment with $900 \mathrm{mg} /$ day resulted in significantly greater reduction in

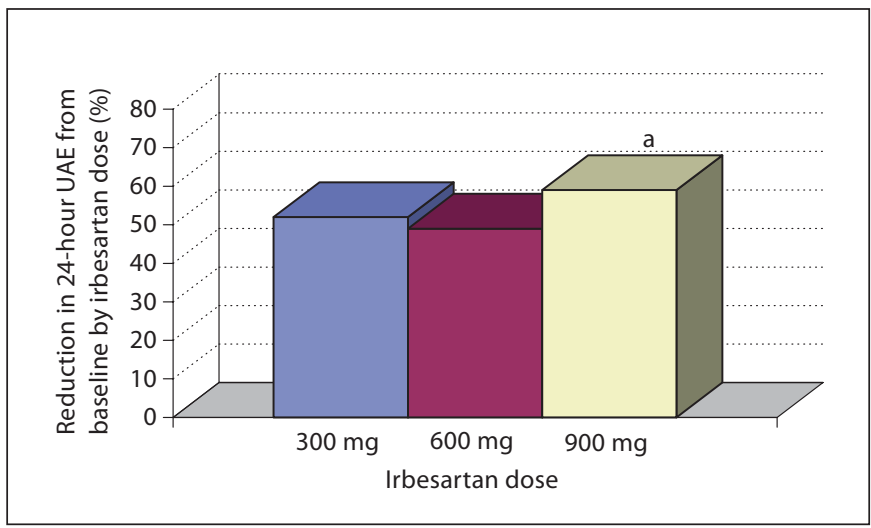

Fig. 1. Reduction in albuminuria with standard versus supratherapeutic dosages of irbesartan in hypertensive patients with type 2 diabetes mellitus and microalbuminuria. Reduction in rate of 24-hour urinary albumin excretion (UAE) with irbesartan 300, 600 , and $900 \mathrm{mg} /$ day is displayed. ${ }^{\mathrm{a}} \mathrm{p}<0.05$ versus 300 and 600 $\mathrm{mg}$ (data from Rossing et al. [46]).

UAE rate of 59\% (95\% CI 54-63\%) compared with the lower doses, that resulted in a 52\% (95\% CI 46-57\%) and $49 \%(95 \%$ CI 43-54\%) $(\mathrm{p}<0.01)$ reduction, respectively (fig. 1). The increased reduction of UAE by higher doses of irbesartan was independent of reductions in systemic blood pressure. With increasing doses, ambulatory blood pressure was reduced from baseline by $8 / 6,9 / 7$, and 9/7 $\mathrm{mm} \mathrm{Hg}$. UAE was reduced significantly more by $900 \mathrm{mg} /$ day irbesartan than by all lower doses, with an additional reduction in UAE of $15 \%$ (2 to 26\%) by irbesartan 900 $\mathrm{mg} / \mathrm{day}$ compared with $300 \mathrm{mg} / \mathrm{day}(\mathrm{p}=0.02)$. There was comparable reduction in ambulatory blood pressure with all doses of irbesartan: an 8- to 9-mm-Hg reduction in systolic blood pressure and a 6- to 7-mm-Hg reduction in diastolic blood pressure. Reasons for discontinuation among the 58 patients who entered the trial were acute myocardial infarction with $300 \mathrm{mg} /$ day $(\mathrm{n}=1)$, ischemic stroke with 300 or $900 \mathrm{mg} /$ day $(\mathrm{n}=2)$, and dizziness and general discomfort $(\mathrm{n}=1)$.

Among the 52 patients who completed the trial, 7 reported mild and transient dizziness with $300 \mathrm{mg} /$ day $(\mathrm{n}=1), 600 \mathrm{mg} / \mathrm{day}(\mathrm{n}=3)$, or $900 \mathrm{mg} /$ day $(\mathrm{n}=3)$. Although there was a significant increase from baseline in plasma potassium levels $(0.3-0.4 \mathrm{mmol} / \mathrm{l})$, no patients developed hyperkalemia ( $>5.5 \mathrm{mmol} / \mathrm{l})$. Hemoglobin levels significantly decreased from the baseline $(8.7 \mathrm{mmol} / \mathrm{l})$ to the endpoint (8.1-8.2 $\mathrm{mmol} / \mathrm{l})$.

Similar results were achieved with supratherapeutic doses of candesartan in a double-blind, randomized, 


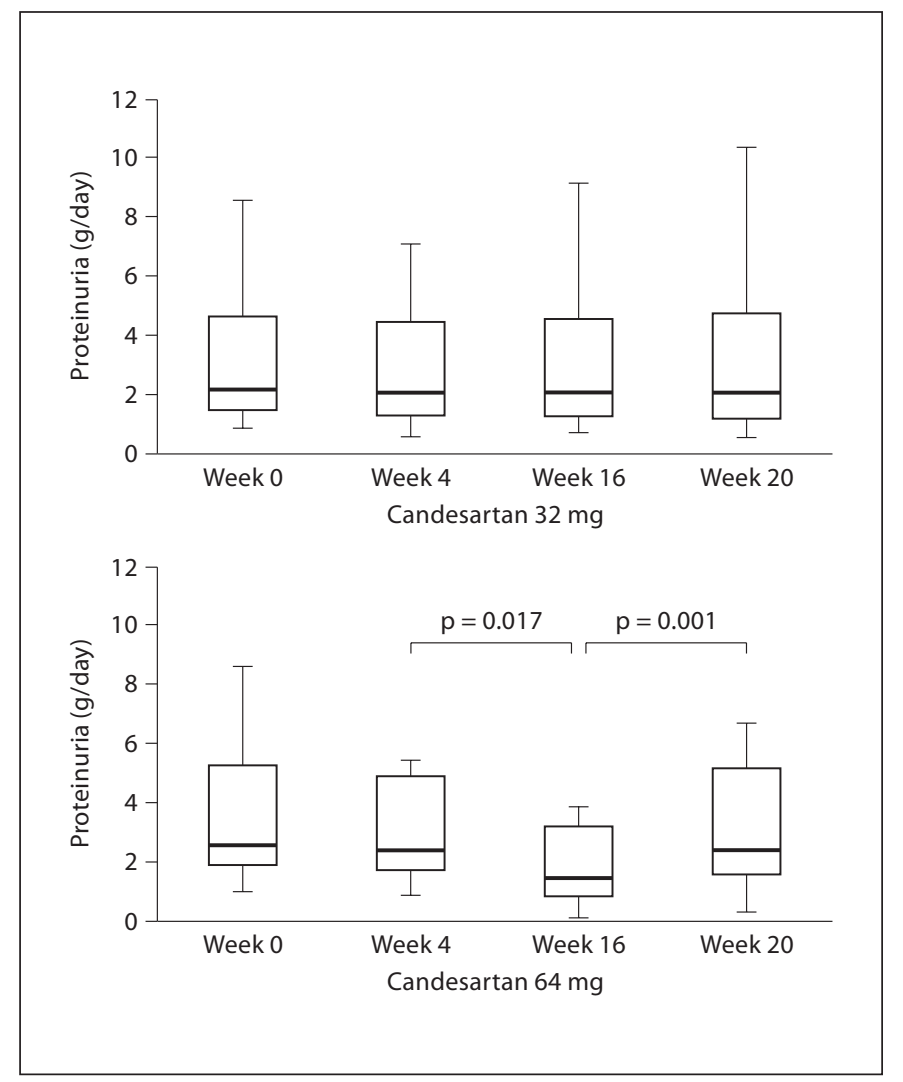

Fig. 2. Reduction in proteinuria with the maximum dose of candesartan indicated for hypertension versus a supratherapeutic dose in patients with CKD and normal to mildly impaired kidney function. Proteinuria is shown at baseline (week 0); after 4 weeks of treatment with $16 \mathrm{mg} /$ day candesartan (week 4); after 12 subsequent weeks of treatment with $32 \mathrm{mg} /$ day (maximum approved dose) or $64 \mathrm{mg} /$ day (week 16), and after 4 subsequent weeks of treatment with $16 \mathrm{mg} /$ day (week 20). Horizontal lines represent means, boxes represent $95 \%$ confidence intervals, and whiskers represent range of proteinuria. $\mathrm{n}=32$ (reproduced with permission from Schmieder et al. [34]).

parallel-group trial in patients with CKD due to diabetes $(n=5)$ or other causes $(n=27)$ with normal or mildly impaired kidney function (rate of protein excretion, 1-10 $\mathrm{g}$ /day) and 3 months of prior treatment with an ACE-I or ARB [34]. Candesartan is indicated for treating hypertension at a dose of $16 \mathrm{mg} /$ day or titrated to $32 \mathrm{mg}$ /day for further reduction in blood pressure [48]. Patients received $16 \mathrm{mg} /$ day candesartan for 4 weeks, then 32 or $64 \mathrm{mg} /$ day for 12 weeks, and finally $16 \mathrm{mg} /$ day for the last 4 weeks. Patients had similar baseline proteinuria (mean $2.14 \mathrm{~g} /$ day (95\% CI 1.45-3.17) and 2.54 g/day (95\% CI 1.91-3.40)). The group that received $32 \mathrm{mg} /$ day showed little change in proteinuria $(2.02 \mathrm{mg} /$ day $(95 \% \mathrm{CI} 1.26-3.26))$, but the

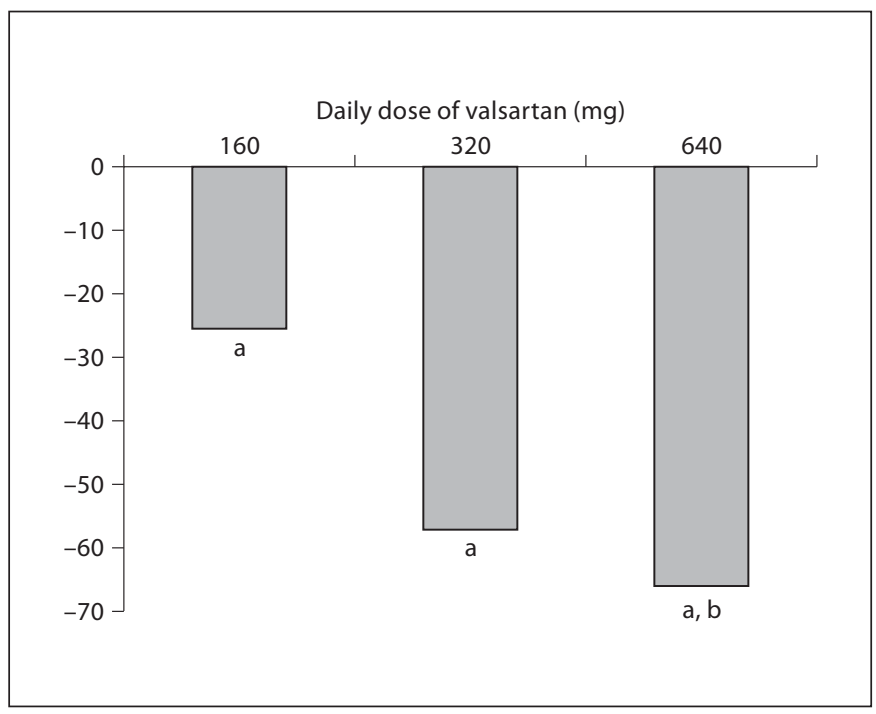

Fig. 3. Decrease in albuminuria with the conventional and maximum indicated doses of valsartan compared with a supratherapeutic dose in hypertensive patients with type 2 diabetes mellitus and elevated proteinuria. ${ }^{\mathrm{a}} \mathrm{p}<0.001$ for within-treatment comparison; ${ }^{b} \mathrm{p}<0.05$ versus $160 \mathrm{mg} . \mathrm{n}=391$ (data from Hollenberg et al. [49]).

group that received $64 \mathrm{mg} /$ day had a significant reduction in proteinuria to $1.42 \mathrm{~g} /$ day $(95 \%$ CI $0.85-2.37$; $\mathrm{p}=$ $0.017)$. A significantly greater reduction in proteinuria occurred with 64 versus $32 \mathrm{mg} /$ day $(-29 \pm 50 \%$ vs. $0 \pm$ $26 \% ; \mathrm{p}=0.012)$. After titration to $16 \mathrm{mg} /$ day, proteinuria significantly increased in the $64-\mathrm{mg} /$ day group $(2.38 \mathrm{~g} /$ day (95\% CI 1.57-3.62)) but not in the 32-mg/day group (2.04 g/day (95\% CI 1.17-3.57)) (fig. 2). No change in blood pressure was detected with the different doses of candesartan, and there was no correlation between blood pressure and proteinuria. There were also no significantly different changes in creatinine clearance or sodium excretion.

In the DROP study, a double-blind study in $391 \mathrm{pa}-$ tients with type 2 diabetes mellitus, hypertension, and elevated proteinuria (urinary protein albumin excretion rate, $20-700 \mu \mathrm{g} / \mathrm{min}$ ), supratherapeutic doses of valsartan were also shown to provide a greater antiproteinuric effect than lower doses [49]. In this trial, patients received valsartan $160 \mathrm{mg} /$ day for 4 weeks and then were randomized to receive the same dosage, 320 or $640 \mathrm{mg} /$ day, for 26 weeks. Valsartan is indicated at $320 \mathrm{mg} /$ day for hypertension [50]. At week 4, all groups had comparable, significant decreases in rate of UAE $(p<0.001)$. At week 30 , patients receiving 320 or $640 \mathrm{mg} /$ day had significantly 
greater reductions from baseline compared with those receiving $160 \mathrm{mg} /$ day $(51,49$, and 25\%, respectively). Patients who received $640 \mathrm{mg} /$ day had a significantly higher rate of $24 \%$ of achieving a normal rate of excretion $(<20$ $\mu \mathrm{g} / \mathrm{min}$ ) compared with those that received $160 \mathrm{mg} / \mathrm{day}$, that had a $12 \%$ rate of achieving a normal rate of excretion $(\mathrm{p}=0.021)$ (fig. 3). All dosages significantly reduced blood pressure $(\mathrm{p}<0.001)$. Patients who received the $640-\mathrm{mg} /$ day dosage had a lower frequency of additional antihypertensive medications yet exhibited a significantly greater decrease in blood pressure compared with patients who received $320 \mathrm{mg} /$ day. Reported adverse effects were associated with the $640-\mathrm{mg} /$ day dosage with a slightly higher incidence of dizziness and headache, but there were no dosage-related increases in other adverse events, including hypotension and hyperkalemia.

Supratherapeutic doses of telmisartan have also demonstrated greater renoprotection compared with lower doses in an open randomized study of 78 hypertensive patients with nondiabetic, proteinuric nephropathy [51]. In this trial, patients received telmisartan $80 \mathrm{mg}$ once daily $(n=40)$ or twice daily $(n=38)$. Telmisartan is indicated for treating hypertension with initial doses of 40 $\mathrm{mg} /$ day and a maximal dose of $80 \mathrm{mg} /$ day [52]. Baseline blood pressure, kidney function, and proteinuria were similar between the treatment groups. During a mean follow-up of $24.6 \pm 2.2$ months patients in both groups exhibited similar blood pressure. In the once-daily treatment group, serum creatinine level increased from $1.6 \pm$ 0.6 to $2.7 \pm 0.9 \mathrm{mg} / \mathrm{dl}(141 \pm 52$ to $239 \pm 80 \mathrm{~mol} / \mathrm{l})$ and estimated creatinine clearance decreased from $68 \pm 30$ to $50 \pm 34 \mathrm{ml} / \mathrm{min}(1.13 \pm 0.50$ to $0.83 \pm 0.57 \mathrm{ml} / \mathrm{s})$, whereas in the twice-daily treatment group, serum creatinine level remained stable ( $1.6 \pm 0.7$ to $1.6 \pm 0.8 \mathrm{mg} /$ $\mathrm{dl}(141 \pm 62$ to $141 \pm 71 \mathrm{~mol} / \mathrm{l}))$ and estimated creatinine clearance values $(67 \pm 38$ to $74 \pm 38 \mathrm{ml} / \mathrm{min}(1.12 \pm 0.63$ to $1.23 \pm 0.63 \mathrm{ml} / \mathrm{s})$ ) changed minimally during the study. $40 \%$ of patients in the twice-daily treatment group exhibited a significantly greater $(\mathrm{p}<0.001)$ decrease in proteinuria compared with $15 \%$ of patients in the oncedaily group that achieved control of proteinuria $(<0.3 \mathrm{~g} /$ $24 \mathrm{~h}$ ) (fig. 4). In neither group was there a significant change in serum potassium levels or lipid profiles.

A recent study evaluated the effect of the telmisartan in combination with amlodipine at increasing doses on UAE rate in 210 hypertensive diabetic patients with microalbuminuria and uncontrolled blood pressure (>130/80 mm Hg) [53]. Patients were randomized to one regimen based on increasing doses of telmisartan (up to $160 \mathrm{mg}$ daily) and fixed 2.5-mg dose of amlodipine, or

Supratherapeutic Doses of ARBs to

Decrease Proteinuria in CKD

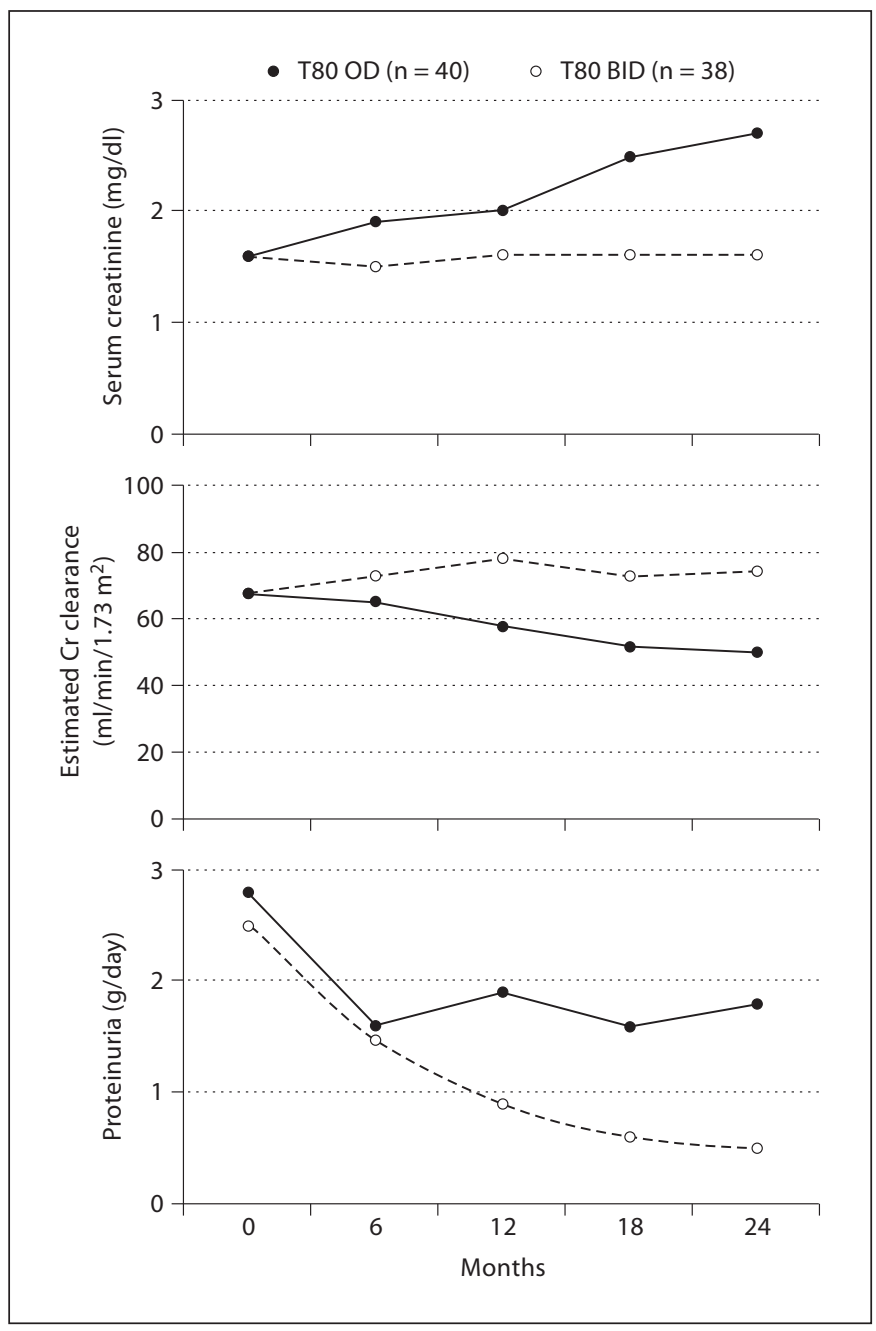

Fig. 4. Creatinine clearance and proteinuria over time in hypertensive patients with nondiabetic, proteinuric nephropathy treated with telmisartan $80 \mathrm{mg}$ once daily compared with $80 \mathrm{mg}$ twice daily (reproduced with permission from Aranda et al. [51]).

another regimen based on increasing doses of amlodipine (up to $10 \mathrm{mg}$ daily) and fixed 40 -mg dose of telmisar$\tan$. A greater reduction of UAE rate was found with increasing doses of telmisartan $(47.5,65.3$, and $77 \%$ for telmisartan 80,120 , and $160 \mathrm{mg} /$ amlodipine $2.5 \mathrm{mg}$ daily, respectively) whereas they were similar at all doses of amlodipine $/ 40 \mathrm{mg}$ telmisartan. Similar decreases in blood pressure values were obtained with both regimens. With increasing doses of telmisartan, systolic/diastolic blood pressure values decreased by $-24 /-21,-23 /-21$, and $-24 /-21 \mathrm{~mm} \mathrm{Hg}$ (all p < 0.001) as compared to baseline. As dosage of amlodipine was increased, blood pressure values decreased by $-25 /-22,-25 /-21$, and $-25 /-22 \mathrm{~mm}$ 
$\mathrm{Hg}$ (all $\mathrm{p}<0.001$ ) versus baseline. A dose effect with telmisartan was also observed in the Incipient to Overt: Angiotensin II Blocker, Telmisartan, Investigation on Type 2 Diabetic Nephropathy (INNOVATION) Study $(\mathrm{n}=514)$ [54]. Patients taking higher doses of telmisartan had lower rates of transition to overt nephropathy $(16.7 \%$ telmisartan $80 \mathrm{mg} ; 22.6 \%$ telmisartan $40 \mathrm{mg}$ ) and higher rates of induced remission of microalbuminuria $(21.2 \%$ telmisartan $80 \mathrm{mg} ; 12.8 \%$ telmisartan $40 \mathrm{mg}$ ).

\section{Conclusions}

Further examination is warranted regarding the use of supratherapeutic doses of ARBs to treat CKD in patients with and without diabetes mellitus. Because dose-response curves have not been established for ARBs in treating CKD, it remains to be assessed whether doses higher than those already used may offer additional renoprotection. The long-term safety of supratherapeutic doses should also be further examined, particularly before use in susceptible elderly patients with diabetes and hypertension [55]. The importance of long-term follow-up and safety concerns over the use of supratherapeutic doses of RAAS inhibitors is reinforced by reports of a few cases ( 1 case with ARB treatment, 4 with ACE-Is) of worsening of azotemia after several months to years of RAAS blockade in patients with CKD (4 cases with diabetes) [56]. However, the likelihood of complications such as hyperkalemia and changes in the serum creatinine concentration can be minimized $[57,58]$.
Additional trials are currently under way to assess the efficacy of supratherapeutic doses of RAAS inhibitors for nephropathy. In August 2004, the Ottawa Health Research Institute initiated a trial in patients with diabetic nephropathy (expected enrollment, $\mathrm{n}=30$ ) to determine whether addition of irbesartan to recommended doses of trandolapril is more effective in decreasing proteinuria compared with high doses of trandolapril [59]. In addition to this, the Institut de Recherches Cliniques de Montréal is conducting a trial in hypertensive patients with diabetes (expected enrollment, $\mathrm{n}=50$ ) to determine if ramipril $10 \mathrm{mg} /$ day combined with telmisartan $80 \mathrm{mg} /$ day is more effective than a higher dose of ramipril (20 $\mathrm{mg} /$ day) in reducing microalbuminuria. This trial is expected to be completed in October 2007 [60]. A third, larger, ongoing trial in patients with diabetic nephropathy, stable hypertension, and moderate to severe proteinuria (expected enrollment, $\mathrm{n}=270$ ) was initiated in April 2003. The aim of this trial is to examine the effects of high doses of candesartan cilexetil (16, 64, and $128 \mathrm{mg} /$ day) on proteinuria (primary endpoint), kidney function (serum creatinine level and 24-hour creatinine clearance), and blood pressure [61].

With more data on supratherapeutic dosing for treating CKD and expected data on the benefits of specific combination therapy versus monotherapy with ACE-I plus ARBs (e.g., results from ONTARGET [24]), an enhanced understanding of how to more optimally approach CKD promises to emerge.

\section{References}

1 National Kidney Foundation-Kidney Disease Outcomes Quality Initiative: K-DOQI clinical practice guidelines and clinical practice recommendations for diabetes and chronic kidney disease. Am J Kidney Dis 2007;49(suppl 2):S12-S154.

$\checkmark 2$ Saydah S, Eberhardt M, Rios-Burrows N, Williams D, Geiss L, Dorsey R, Centers for Disease Control and Prevention: Prevalence of chronic kidney disease and associated risk factors - United States, 1999-2004. MMWR Morb Mortal Wkly Rep 2007;56:161-165.

3 US Renal Data System: USRDS 2005 Annual Data Report: Atlas of End-Stage Renal Disease in the United States. Bethesda, National Institutes of Health, National Institute of Diabetes and Digestive and Kidney Diseases, 2006. http://www.usrds.org/adr.htm.
4 Hsu C, Vittinghoff E, Lin F, Shilpak MG: Incidence of end-stage renal disease is increasing faster than the prevalence of chronic renal insufficiency. Ann Intern Med 2004;141: 95-101.

5 Mainous AG III, Baker R, Koopman RJ, Saxena S, Diaz VA, Everett CJ, Majeed A: Impact of the population at risk of diabetes and projections of diabetes burden in the United States: an epidemic on the way. Diabetologia 2007;50:934-940

6 Praga M: Therapeutic measures in proteinuric nephropathy. Kidney Int 2005;68:S137S141.

7 Kelley K, Aricak OT, Light RP, Agarwal R: Proteinuria is a determinant of quality of life in diabetic nephropathy: modeling lagged effects with path analysis. Am J Nephrol 2007;27:488-494.
8 Atkins RC, Briganti EM, Lewis JB, Hunsicker LG, Braden G, Champion de Crespigny PJ, DeFerrari G, Drury P, Locatelli F, Wiegmann TB, Lewis EJ: Proteinuria reduction and progression to renal failure in patients with type 2 diabetes mellitus and overt nephropathy. Am J Kidney Dis 2005;45:281287.

$\checkmark 9$ De Zeeuw D, Remuzzi G, Parving HH, Keane WF, Zhang Z, Shahinfar S, Snapinn S, Cooper ME, Mitch WE, Brenner BM: Proteinuria, a target for renoprotection in patients with type 2 diabetic nephropathy: lessons from RENAAL. Kidney Int 2004;65: 2309-2320. 
-10 Jafar TH, Stark PC, Schmid CH, Landa M, Maschio G, Marcantoni C, de Jong PE, de Zeeuw D, Shahinfar S, Ruggenenti P, Remuzzi G, Levey AS, AIPRD Study Group: Proteinuria as a modifiable risk factor for the progression of non-diabetic renal disease. Kidney Int 2001;60:1131-1140.

11 Agarwal R: Reproducibility of renal function measurements in adult men with diabetic nephropathy: research and clinical implications. Am J Nephrol 2007;27:92-100.

-12 Taguma Y, Kitamoto Y, Futaki G, Ueda H, Monma H, Ishizaki M, Takahashi H, Sekino $\mathrm{H}$, Sasaki Y: Effect of captopril on heavy proteinuria in azotemic diabetics. N Engl J Med 1985;313:1617-1620.

13 Agarwal R, Andersen MJ: Correlates of systolic hypertension in patients with chronic kidney disease. Hypertension 2005;46:514520.

14 Kakuta H, et al: Telmisartan has the strongest binding affinity to angiotensin II type 1 receptor: comparison with other angiotensin II type 1 receptor blockers. Int J Clin Pharmacol Res 2005;25:41-46.

15 Agarwal R: Add-on angiotensin receptor blockade with maximized ACE inhibition. Kidney Int 2001;59:2282-2289.

-16 Agarwal R: Proinflammatory effects of oxidative stress in chronic kidney disease: role of additional angiotensin II blockade. Am J Physiol Renal Physiol 2003;284:F863-F869.

-17 GISEN Group (Gruppo Italiano di Studi Epidemiologici in Nefrologia): Randomised placebo-controlled trial of effect of ramipril on decline in glomerular filtration rate and risk of terminal renal failure in proteinuric, non-diabetic nephropathy. Lancet 1997;349. 1857-1863.

18 Ruggenenti P, Perna A, Mosconi L, Pisoni R, Remuzzi G: Urinary protein excretion rate is the best independent predictor of ESRF in non-diabetic proteinuric chronic nephropathies. Kidney Int 1998;53:1209-1216.

19 Ruggenenti P, Perna A, Remuzzi G; on behalf of the Investigators of the GISEN Group: Retarding progression of chronic renal disease: the neglected issue of residual proteinuria. Kidney Int 2003;63:2254-2261.

-20 Peterson JC, Adler S, Burkart JM, Greene T, Hebert LA, Hunsicker LG, King AJ, Klahr S, Massry SG, Seifter JL: Blood pressure control, proteinuria, and the progression of renal disease. The Modification of Diet in Renal Disease Study. Ann Intern Med 1995;123: 754-762.

-21 Hillege HL, Fidler V, Diercks GFH, van Gilst WH, de Zeeuw D, van Veldhuisen DJ, Gans RO, Janssen WM, Grobbee DE, de Jong PE, Prevention of Renal and Vascular End-Stage Disease (PREVEND) Study Group: Urinary albumin excretion predicts cardiovascular and noncardiovascular mortality in the general population. Circulation 2002;106:17771782 .

Supratherapeutic Doses of ARBs to

Decrease Proteinuria in CKD
22 Forbes JM, Fukami K, Cooper ME: Diabetic nephropathy: where hemodynamics meets metabolism. Exp Clin Endocrinol Diabetes 2007;115:69-84.

23 Hoffmann S, Podlich D, Hahnel B, Kriz W, Gretz N: Angiotensin II type 1 receptor overexpression in podocytes induces glomerulosclerosis in transgenic rats. J Am Soc Nephrol 2004;15:1475-1487.

24 Teo K, Yusuf S, Sleight P, Anderson C, Mookadam F, Ramos B, Hilbrich L, Pogue J, Schumacher H, ONTARGET/TRANSCEND Investigators: Rationale, design, and baseline characteristics of two large, simple, randomized trials evaluating telmisartan, ramipril, and their combination in high-risk patients: the Ongoing Telmisartan Alone and in Combination with Ramipril Global Endpoint Trial/Telmisartan Randomized Assessment Study in ACE Intolerant Subjects with Cardiovascular Disease (ONTARGET/TRANSCEND) trials. Am Heart J 2004; 148:52-61.

25 Heart Outcomes Prevention Evaluation Study Investigators: Effects of an angiotensin-converting-enzyme inhibitor, ramipril, on cardiovascular events in high-risk patients. N Engl J Med 2000;342:145-153.

26 ONTARGET: ONgoing Telmisartan Alone and in Combination With Ramipril Global Endpoint Tria Parallel Trial. TRANSCEND Telmisartan Randomized AssessmeNt Study in aCE iNtolerant Subjects With Cardiovascular Disease Trial. Available at: http:// w w w.clinicaltrials.gov/ct/show/ NCT00153101?order $=1$.

27 Heeg JE, de Jong PE, van der Hem GK, de Zeeuw D: Efficacy and variability of the antiproteinuric effect of ACE inhibition by lisinopril. Kidney Int 1989;36:272-279.

28 Tozawa M, Iseki K, Iseki C, Oshiro S, Ikemiya Y, Takishita S: Influence of smoking and obesity on the development of proteinuria. Kidney Int 2002;62:956-962.

29 Fried LF, Orchard TJ, Kasiske BL: Effect of lipid reduction on the progression of renal disease: a meta-analysis. Kidney Int 2001;59: 260-269.

30 Van den Meiracker AH, Baggen RG, Pauli S, Lindemans A, Vulto AG, Poldermans D, Boomsma F: Spironolactone in type 2 diabetic nephropathy: effects on proteinuria, blood pressure and renal function. J Hypertens 2006;24:2285-2292.

31 Bianchi S, Bigazzi R, Campese VM: Longterm effects of spironolactone on proteinuria and kidney function in patients with chronic kidney disease. Kidney Int 2006;70:21162123.

32 Azizi M, Menard J, Bissery A, Guyenne TT, Bura-Riviere A, Vaidyanathan S, Camisasca RP: Pharmacologic demonstration of the synergistic effects of a combination of the renin inhibitor aliskiren and the AT1 receptor antagonist valsartan on the angiotensin IIrenin feedback interruption. J Am Soc Nephrol 2004;15:3126-3133.
Palmer BF: Proteinuria as a therapeutic target in patients with chronic kidney disease. Am J Nephrol 2007;27:287-293.

34 Schmieder RE, Klingbeil AU, Fleischmann EH, Veelken R, Delles C: Additional antiproteinuric effect of ultrahigh dose candesartan: a double-blind, randomized, prospective study. J Am Soc Nephrol 2005;16: 3038-3045.

35 Vogt L, Navis G, de Zeeuw D: Individual titration for maximal blockade of the renin angiotensin system in proteinuric patients: a feasible strategy? J Am Soc Nephrol 2005; 16(suppl 1):S53-S57.

36 Textor SC, Gephardt GN, Bravo EL, Tarazi RC, Fouad FM, Tubbs R, McMahon JT: Membranous glomerulopathy associated with captopril therapy. Am J Med 1983;74: 705-712.

37 Hoorntje SJ, Kallenberg CG, Weening JJ, Donker AJ, The TH, Hoedemaeker PJ: Immune-complex glomerulopathy in patients treated with captopril. Lancet 1980;1:12121215.

38 Sturgill BC, Shearlock KT: Membranous glomerulopathy and nephritic syndrome after captopril therapy. JAMA 1983;250:23432345 .

39 Weinberg AJ, Zappe DH, Ashton M, Weinberg MS: Safety and tolerability of high-dose angiotensin receptor blocker therapy in patients with chronic kidney disease: a pilot study. Am J Nephrol 2004;24:340-345.

40 Weinberg AJ, Zappe DH, Ramadugu R, Weinberg MS: Long-term safety of high-dose angiotensin receptor blockers therapy in hypertensive patients with chronic kidney disease. J Hypertens Suppl 2006;24:S95-S99.

41 Nagai M, Horikoshi K, Izumi T, Seki S, Taniguchi M, Taniguchi I, Mochizuki S: Cardioprotective action of perindopril versus candesartan in renovascular hypertensive rats. Cardiovasc Drugs Ther 2004;18:353-362.

42 Porteri E, Rodella L, Rissoni D, Rezzani R, Paiardi S, Sleiman I, De Ciuceis C, Boari GE, Castellano M, Bianchi R, Agabiti-Rosei E: Effects of olmesartan and enalapril at low or high doses on cardiac, renal and vascular interstitial matrix in spontaneously hypertensive rats. Blood Press 2005;14:184-192.

43 Fujihara CK, Velho M, Malheiros DM, Zatz R: An extremely high dose of losartan affords superior renoprotection in the remnant model. Kidney Int 2005;67:1913-1924.

44 Ma L-J, Nakamura S, Aldigier JC, Rossini M, Yang H, Liang X, Nakamura I, Marcantoni C, Fogo AB: Regression of glomerulosclerosis with high-dose angiotensin inhibition is linked to decreased plasminogen activator inhibitor-1. J Am Soc Nephrol 2005;16:966976.

45 Yu C, Gong R, Rifai A, Tolbert EM, Dworkin LD: Long-term, high-dosage candesartan suppresses inflammation and injury in chronic kidney disease: nonhemodynamic renal protection. J Am Soc Nephrol 2007; 18: 750-759. 
46 Rossing K, Schjoedt KJ, Jemsen BR, Boomsma F, Parving $\mathrm{HH}$ : Enhanced renoprotective effects of ultrahigh doses of irbesartan in patients with type 2 diabetes and microalbuminuria. Kidney Int 2005;68:1190-1198.

47 Avapro $^{\circledR}$ (irbesartan) Prescribing Information. New York, Bristol-Myers Squibb Sanofi-Synthelabo Partnership, October 2005.

48 Atacand HCT Tablets ${ }^{\circledR}$ (candesartan) Prescribing Information. Wilmington, AstraZeneca, December 2005

49 Hollenberg NK, Parving HH, Viberti G, Remuzzi G, Ritter S, Zelenkofske S, Kandra A, Daley WL, Rocha R: Albuminuria response to very high-dose valsartan in type 2 diabetes mellitus. J Hypertens 2007;25:19211926.

50 Diovan $^{\circledR}$ (valsartan) Prescribing Information. East Hanover, Novartis Pharmaceutical Corp, November 2006.

-51 Aranda O, Segura J, Ruilope LM, Aranda FJ, Frutos MA, Lopez V, Lopez de Novales E: Long-term renoprotective effects of standard versus high doses of telmisartan in hypertensive nondiabetic nephropathies. Am J Kidney Dis 2005;46:1074-1079.
52 Micardis $^{\circledR}$ (telmisartan) Prescribing Information. Ridgefield, Boehringer Ingelheim Pharmaceuticals, Inc, May 2006.

53 Fogari R, Derosa G, Zoppi A, Preti P, Lazzari P, Destro M, Fogari E, Rinaldi A, Mugellini A: Effect of telmisartan-amlodipine combination at different doses on urinary albumin excretion in hypertensive diabetic patients with microalbuminuria. Am J Hypertens 2007;20:417-422.

54 Makino H, Haneda M, Babazono T, Moriya T, Ito S, Iwamoto Y, Kawamori R, Takeuchi M, Katayama S, INNOVATION Study Group: Prevention of transition form incipient to overt nephropathy with telmisartan in patients with type 2 diabetes. Diabetes Care 2007;30:1577-1578.

55 Onuigbo MA, Onuigbo NT: Use of ultrahigh RAAS blockade: implications for exacerbation and renal function. Kidney Int 2006;69: 194-195.

56 Onuigbo MAC, Onuigbo NTC: Late onset renal failure from angiotensin blockade (LORFFAB): a prospective thirty-month Mayo Health System clinic experience. Med Sci Monit 2005;11:CR462-CR469.
57 Palmer BF: Renal dysfunction complicating treatment of hypertension. N Engl J Med 2002;347:1256-1261.

58 Palmer BF: Managing hyperkalemia caused by inhibitors of the renin-angiotensin-aldosterone system. N Engl J Med 2004;351:585592.

59 High dose ACE inhibitor therapy versus combination ACE and ARB therapy. Clinical Trials.gov Identifier NCT00212901. Available at: http://clinicaltrials.gov/ct/show/ NCT00212901. Accessed August 9, 2007.

60 Higher dose of ramipril versus addition of telmisartan-ramipril in hypertension and diabetes. ClinicalTrials.gov Identifier NCT00208221. Available at: http://clinicaltrials.gov/ct/show/NCT00208221. Accessed August 8, 2007.

61 High doses of candesartan cilexetil on the reduction of proteinuria. ClinicalTrials.gov Identifier NCT00242346. Available at: http:// clinicaltrials.gov/ct/show/NCT00242346. Accessed August 9, 2007. 